\title{
Identification and Validation of Novel Biomarkers for HBV-Associated Hepatocellular Carcinoma, Liver Fibrosis/Cirrhosis and Chronic Hepatitis: A Case Control Study
}

\section{Dandan Zhao}

The Third Hospital of Hebei Medical University https://orcid.org/0000-0002-9577-5698

\section{Xiaoxiao Zhang}

Hebei Medical University Third Affiliated Hospital

\section{Yuhui Tang}

Hebei Medical University Third Affiliated Hospital

\section{Peilin Guo}

Hebei Medical University Third Affiliated Hospital

\section{Rong Ai}

Hebei Medical University Third Affiliated Hospital

Mengmeng Hou

Hebei Medical University Third Affiliated Hospital

\section{Yiqi Wang}

Hebei Medical University Third Affiliated Hospital

\section{Xiwei Yuan}

Hebei Medical University Third Affiliated Hospital

\section{Luyao Cui}

Hebei Medical University Third Affiliated Hospital

\section{Yuguo Zhang}

Hebei Medical University Third Affiliated Hospital

\section{Suxian Zhao}

Hebei Medical University Third Affiliated Hospital

\section{Wencong Li}

Hebei Medical University Third Affiliated Hospital

\section{Yang Wang}

Hebei Medical University Third Affiliated Hospital

\section{Xiaoye Sun}

Hebei Medical University Third Affiliated Hospital

Lingdi Liu

Hebei Medical University Third Affiliated Hospital 


\section{Shiming Dong}

Hebei Medical University Third Affiliated Hospital

\section{Lu Li}

Hebei Medical University Third Affiliated Hospital

\section{Wen Zhao}

Hebei Medical University Third Affiliated Hospital

\section{Yuemin Nan ( $D$ nanyuemin@163.com )}

Hebei Medical University Third Affiliated Hospital

\section{Research}

Keywords: HBV-associated liver diseases, transcriptome sequencing technology, SHC1, SLAMF8, IL-32

Posted Date: September 15th, 2021

DOI: https://doi.org/10.21203/rs.3.rs-859946/v1

License: (c) (1) This work is licensed under a Creative Commons Attribution 4.0 International License.

Read Full License 


\section{Abstract}

\section{Background}

At present, there are no accurate diagnostic biomarkers for distinguishing among hepatitis B virus (HBV)related liver diseases. This research aimed to identify and validate a novel biomarker panel in patients with HBV-related hepatocellular carcinoma (HCC), liver fibrosis/liver cirrhosis (LF/LC) and chronic hepatitis B (CHB).

\section{Methods}

Transcriptomics sequencing was conducted on a total of 19 liver tissues of the four groups. The hub mRNAs were identified using weighted gene co-expression network analysis (WGCNA) and short timeseries expression miner (STEM) method. The expression levels of selected mRNAs and proteins were assessed by quantitative real-time polymerase chain reaction (qRT-PCR) using both liver tissues and peripheral blood mononuclear cells (PBMCs) and immunohistochemical (IHC) staining in liver tissues, respectively. Then, the expression activities of the screened targets were detected by enzyme-linked immunosorbent assay (ELISA) using the plasma samples from 200 and 400 subjects in the validation and testing sets, respectively. Finally, receiver operating characteristic (ROC) curve analysis was carried out to evaluate the diagnostic performance of each mRNA biomarker.

\section{Results}

STEM analysis revealed 25 mRNAs exhibited an increasing trend in the four groups; while 9 hub mRNAs were identified by using WGCNA. Of note, the results of qRT-PCR and immunohistochemical analyses demonstrated that SHC adaptor protein 1 (SHC1), SLAM family member 8 (SLAMF8), and interleukin-32 (IL-32) exhibited a gradually increasing trend in the four groups. Subsequent ELISA tests on the validation cohort demonstrated that the plasma levels of SHC1, SLAMF8 and IL-32 were remarkably elevated in HCC group compared to the remaining three groups. Furthermore, a diagnostic model APFSSI (age, PLT, ferritin, SHC1, SLAMF8 and IL-32) was established to distinguish HCC from LF/LC (AUC=0.904), LF/LC from $\mathrm{CHB}(\mathrm{AUC}=0.924)$, and $\mathrm{CHB}$ from healthy controls $(A U C=0.966)$. Finally, the results in the test set were consistent with those in the validation set.

\section{Conclusions}

SHC1, SLAMF8 and IL-32 can differentiate among HCC patients, LF/LC patients, CHB patients and healthy controls. More importantly, the combination of age, PLT, ferritin, SHC1, SLAMF8, and IL-32 (APFSSI model) greater improves the diagnostic accuracy of HBV-associated liver diseases.

\section{Background}

Hepatitis B virus (HBV) infection is a global health issues, especially in developing countries, which affects 257 million people and causes 887000 deaths annually [1]. The three main stages in the 
progression of HBV infection are hepatocellular carcinoma (HCC), liver fibrosis/liver cirrhosis (LF/LC) and chronic hepatitis $\mathrm{B}$ (CHB), or widely recognized as "hepatitis trilogy" [2]. CHB is commonly known for the heterogeneous patient features and long course of disease progression [3], while LF is a wound healing process; both are necessary stages from chronic liver disease to cirrhosis, and even HCC [4]. Despite great advancements in diagnosis and treatment, the majority of HCC patients have unfavorable outcomes, with a 5-year overall survival rate of $<50 \%$ [5]. Thus, it is of great importance to identify at-risk patients for early management of this disease [6]. Currently, there are few specific clinical noninvasive diagnostic methods for HBV-related liver diseases. The gold standard of diagnosing LF or liver cancer still underlies a tissue pathology-based approach which known as an invasive procedure with potential risks or complications [6, 7]. Besides, alpha-fetoprotein (AFP) is among the most common biomarkers for early detection and monitoring of HCC patients [8]. However, the low accuracy and reliability of AFP have hindered its implementation into the clinic [9]. Thus, a novel non-invasive method for diagnosing and distinguishing between HCC, LC/LF and CHB is urgently needed in order to further improve the survival outcomes of these patients.

To our knowledge, the mRNA expression profiles obtained from different models are varied significantly due to different stages of HBV-related liver diseases [10]. As mRNA can be translated into protein and blood sample is easily available for clinical laboratory experiments, our study aimed to verify potential mRNA biomarkers for early-onset and predict the progress of HBV-associated liver diseases [11]. First, transcriptomics sequencing was performed on liver tissues to assess differentially expressed mRNAs in HCC, LC/LF, CHB and control groups. Second, based on the differentially expressed mRNAs, we conducted quantitative real-time polymerase chain reaction (qRT-PCR) and immunohistochemical (IHC) analyses to verify the candidate biomarkers for differentiating between "HCC and LF/LC", "LF/LC and CHB", "CHB and healthy controls". Third, we evaluated the diagnostic power of selected biomarkers in a retrospective, cross-sectional cohort, and developed an APFSSI model based on age, platelet count, ferritin, SHC adaptor protein 1 (SHC1), SLAM family member 8 (SLAMF8), and interleukin-32 (IL-32) levels. Finally, the diagnostic values of SHC1, SLAMF8, IL-32 and APFSSI model were further validated in another independent retrospective cohort.

\section{Materials And Methods}

Study subjects. In this cross-sectional study, we collected liver or blood samples from $180 \mathrm{HBV}$-realated HCC patients, $180 \mathrm{HBV}$-associated LF/LC patients, $180 \mathrm{CHB}$ patients and 180 healthy controls at the Third Hospital of Hebei Medical University between January 2017 and February 2021 according to our inclusion criteria. These subjects were randomly categorized into training, validation and testing cohorts for the identification and validation of novel biomarkers. Routine blood tests and liver biochemical tests were assessed in the local laboratories. Baseline and clinical data of the studied subjects were collected. Ethical approval for this study was obtained from the Ethics Committee of the Third Hospital of Hebei Medical University. All participants provided written informed consent prior to study enrollment. The experimental protocol was performed in compliance with the 1964 Helsinki Declaration or comparable standards 
Sample preparation. Fresh frozen liver tissues were used for RNA-seq and PCR assay, while formalin-fixed and paraffin-embedded (FFPE) samples were used for IHC analysis. PBMCs (peripheral blood mononuclear cells) were isolated from the whole blood of HBV-related liver disease patients and control subjects through density-gradient centrifugation method using Ficoll medium (Solarbio Life Sciences, Beijing, China). Blood samples were withdrawn from all subjects, and plasma samples were stored at $-80^{\circ} \mathrm{C}$. The plasma levels of candidate biomarkers were assessed by commercial ELISA kits.

Transcriptomic and bioinformatic analyses. As shown in Fig. 1, transcriptome sequencing technology was conducted on HCC patients $(n=5)$, LF/LC patients $(n=5)$, CHB patients $(n=5)$ and healthy controls $(n=4)$. The detailed protocols for both transcriptomic and bioinformatic analyses are summarized in the Supplemental Methods. Briefly, Trizol DP431 reagent (Tiangen, Beijing, China) was used to isolate total RNA. Then, paired-end libraries were sequenced by Illumina Novaseq ${ }^{\text {TM }} 6000$ (LC Bio, China). WGCNA package in $\mathrm{R}$ software

(https://horvath.genetics.ucla.edu/html/CoexpressionNetwork/Rpackages/WGCNA/Tutorials/) was used to uncover the relationships among corresponding genes. Differentially expressed genes were clustered by STEM method (http://www.cs.cmu.edu/ jernst/stem/), and the statistically significant $(P<0.05)$ profile boxes were coloured.

QRT-PCR analysis. The mRNA expression of each target gene was detected by TB Green ${ }^{\text {TM }}$ Premix Ex Taq $^{\text {TM }}$ II (Tli RNaseH Plus; Takara, Japan) using an ABI 7500 RT-PCR system (Applied Biosystems, Carlsbad, CA). Primer sequences are listed in Supplemental Table 1. GAPDH expression was included as an internal control [12]. The detailed method is described in the Supporting Information.

IHC staining. IHC was carried out according to a previous method [12]. First, the sections were dewaxed, dehydrated and blocked with blocking serum. Next, the sections were exposed to the antibody against SHC (1:100, Abways), SLAMF8 (1:100, Origene), IL-32 (1:100, Proteintech), integrin subunit beta 2 (ITGB2/CD18, 1:200, Proteintech) or mesencephalic astrocyte-derived neurotrophic factor (MANF/ARMET, 1:200, Proteintech). After that, the sections were exposed to the HRP-conjugated secondary antibody (Proteintech) for $1 \mathrm{~h}$. Lastly, all sections were visualized with 3,3'-diaminobenzidine, and counterstained with hematoxylin. Integral optical density (IOD) was recorded at $\times 400$ magnification in 10 nonoverlapping fields per sample using an Image-Pro Plus v6.0 software.

Statistical analysis. SPSS v26.0, MedCalc v15.0 and GraphPad Prism v8.0 software were employed to perform the statistical tests. Continuous variables were presented as medians (interquartile ranges) or means \pm standard deviations. Kruskal-Wallis $\mathrm{H}$ test or one-way ANOVA was used for evaluating the differences between groups. Frequency data were shown as numbers and percentages, and were analyzed with the Chi-squared test. Independent diagnostic factors for HBV-associated liver diseases were identified by multivariate ordinal logistic regression analysis. The best threshold/cut-off value for the relative expression of each candidate biomarker in HCC, LF/LC and CHB patients were determined by ROC curve analyses using MedCalc software. All tests were two-tailed, and a $P$-value $<0.05$ was deemed statistically significant. 


\section{Results}

\subsection{High-throughput sequencing of mRNAs from CON, CHB, LF/LC and HCC}

Figure 1 shows the overall design of the study. A total of $332,720,614,405,844,258,425,724,230$ and 430,992,628 reads were sequenced from CON, CHB, LF/LC, and HCC samples, respectively. For CON samples, 314,022,012 clean reads were obtained, which accounted for $94.4 \%$ of reads. Meanwhile, 384,396,180, 404,504,412 and 407,007,164 clean reads were obtained for CHB, LF/LC and HCC samples, respectively. We sought to obtain the sequences of mRNAs shared among the four groups.

\subsection{Identification of candidate biomarkers for the progression of HBV-related diseases}

Bioinformatic analysis was then performed on all sequenced mRNAs to identify the key biomarkers in the four groups. Compared with the CON group, 1,581 differential expressed mRNAs, including 901 upregulated and 680 downregulated, were detected in the CHB group, 2,141 differential expressed mRNAs, including 1,493 upregulated and 648 downregulated in the LF/LC group, and 1588 differential expressed mRNAs, including 1,130 upregulated and 458 downregulated mRNAs, in the HCC group (Fig. S1A). Then, we used Venn and Volcano maps to analyze differentially expressed mRNAs (Fig. S1B-E). To determine the key genes and modules involved in HBV-related liver diseases, WGCNA was conducted to reveal the highly correlated gene pairs as well as the co-expression networks. As shown in Fig. 2A-C, the power of $\beta$ was fixed at 6 to establish a scale-free network, and the hierarchical clustering dendrogram identified 30 gene modules. As we were interested in the potential biomarkers that could be practical and convenient for predicting the progression of HBV-associated liver diseases, the greenyellow, green, turquoise and white modules were screened out. Subsequently, differentially expressed mRNAs were clustered by STEM method, and the results demonstrated that 25 mRNAs were highly expressed among CON, CHB, LF/LC and HCC groups (Fig. 2D, E). By combining with WGCNA analysis, 9 progressively overexpressed mRNAs, such as SHC1, SLAMF8, IL-32, ITGB2, MANF, tandem C2 domains, nuclear (TC2N), synaptopodin (SYNPO), UDP-glucose pyrophosphorylase 2 (UGP2), EGF-containing fibulin extracellular matrix protein 1 [EFEMP1], were chosen for further analyses. KEGG pathway and GO enrichment analyses on these 9 mRNAs indicated that the functions were primarily related to natural killer cell mediated cytotoxicity, protein binding, and metalion binding (Fig. 2F, G).

\subsection{Verification of progressively elevated mRNA abundance through qRT-PCR}

The expression levels of 9 progressively elevated mRNAs were verified with qRT-PCR in liver tissues ( $\mathrm{n}=5$ per group). Of these, 8 mRNAs (SHC1, SLAMF8, IL-32, ITGB2, MANF, TC2N, SYNPO and EFEMP1) showed a gradually increasing trend in the four groups (Fig. 3). We further performed qRT-PCR on PBMCs ( $\mathrm{n}=20$ per group), and 3 mRNAs (SHC1, SLAMF8 and IL-32) had the same expression trends as those observed in liver tissues (Fig. 3). Our qRT-PCR data showed that EFEMP1 has an increasing trend in liver tissues, but its expression in PBMCs is too low to be detected, so we didn't show these results in the figure. Recent studies have shown that ITGB2 was elevated in many malignant tumors [13, 14], and Liang 
Zhang et al. [15] suggested that the expression of ITGA2 was higher in liver cancer tissues than those in para-carcinoma tissues and ITGB2 had a close relationship with ITGA2. Thus, we were curious whether the expression of ITGB2 was elevated in hepatocellular carcinoma. Jingyi He et al. [16] showed that MANF was overexpressed in HCC, but Jun Liu et al. [17] found that MANF mRNA and protein levels were lower in HCC tissues versus adjacent noncancer tissues. So we wonder whether he expression of MANF was higher in liver cancer. To sum up, we selected five candidate mRNAs (SHC1, SLAMF8, IL-32, ITGB2 and MANF) for further verification.

\subsection{IHC staining for SHC1, SLAMF8, IL-32, ITGB2 and MANF in normal and pathologically altered livers}

The expression activities of SHC1, SLAMF8, IL-32, ITGB2 and MANF in liver tissues were detected by IHC staining ( $n=5$ per group). With an increase in the severity of HBV-related liver diseases, the IHC intensities of SHC1 and SLAMF8 were gradually elevated (Fig. 4). IOD analysis indicated that the hepatic expression of IL-32 was the highest in HCC patients, followed by LF/LC patients, CHB patients and control subjects (Fig. 4). Besides, the expression activities of ITGB2 and MANF were markedly higher in LF/LC tissues than in CHB and healthy tissues. However, ITGB2 and MANF levels were found to be declined in the HCC tissues when compared to those in LF/LC tissues (Fig. 4).

\subsection{Preliminary validation of the candidate biomarkers via ELISA}

As shown in Table 1, the proportion of male participants, age, aspartate transaminase (AST), ferritin, FIB4 , and APRI levels were markedly increased among the four groups, whereas the platelet count (PLT), white blood cell count (WBC) and albumin (ALB) levels were reduced.

Notably, the plasma levels of SHC1 were remarkably elevated in HCC patients compared to $L F / L C$ patients, CHB patients and control subjects $(10.7 \pm 2.0$ vs. $9.7 \pm 1.7,7.5 \pm 1.7$ and $4.6 \pm 1.3$ $\mathrm{ng} / \mathrm{ml}$, respectively, $P<0.001$, Table 1$)$. As the disease progressed, the median values of SLAMF8 were obviously increased compared with those measured previously $(P<0.001$, Table 1$)$, which were 8.8, 6.9, 6.1 and 4.9 in the HCC, LF/LC, CHB and healthy control groups, respectively. We determined the mean IL32 concentrations of $78.3 \pm 17.5 \mathrm{pg} / \mathrm{mL}$ for HCC samples, $62.3 \pm 16.0 \mathrm{pg} / \mathrm{mL}$ for LF/LC samples, $49.1 \pm 13.8$ $\mathrm{pg} / \mathrm{mL}$ for $\mathrm{CHB}$ samples and $32.3 \pm 11.7 \mathrm{pg} / \mathrm{mL}$ for control samples, which were significantly different among these groups $(P<0.001$, Table 1$)$.

\subsection{Verifying the predictive mRNA panel in the validation set}

Ten variables (gender, age, WBC, PLT, ALB, AST, ferritin, SHC1, SLAMF8, and IL-32) were identified by univariate ordinal regression analysis (all $P<0.001$, Table 2). These variables were further subjected to multivariate ordinal regression analysis, and significant differences were observed for the following variables: age $(\mathrm{OR}=1.071,95 \% \mathrm{Cl}=1.036-1.107, P<0.001), \mathrm{PLT}(\mathrm{OR}=0.988,95 \% \mathrm{Cl}=0.981-0.995, P=0.002)$, ferritin (OR=1.003, 95\% Cl=1.001-1.006, $P=0.014)$, SHC1 (OR=2.077, 95\% Cl=1.648-2.618, $P<0.001)$, SLAMF8 (OR=2.104, 95\%Cl=1.583-2.796, $P<0.001)$, and IL-32 (OR=1.054, 95\% Cl=1.025-1.083, $P<0.001)$. 
When differentiating between CHB and healthy control, the AUC values of age, PLT, ferritin, SHC1, SLAMF8 and IL-32 were $0.744,0.699,0.688,0.900,0.744$ and 0.821 , respectively (Table 3 , Fig. 5). Accordingly, the cut-off values of age, PLT, ferritin, SHC1, SLAMF8 and IL-32 were 36 years old, $195 \times 10^{9} / \mathrm{L}, 90.60 \mathrm{ng} / \mathrm{mL}, 5.03 \mathrm{ng} / \mathrm{mL}, 4.94 \mathrm{ng} / \mathrm{mL}$ and $48.29 \mathrm{pg} / \mathrm{mL}$, respectively. When discriminating CHB patients from LF/LC patients, age alone yielded an AUC of 0.592 with $58.0 \%$ sensitivity and $62.0 \%$ specificity at the threshold of 42 years old, PLT alone yielded an AUC of 0.812 with $66.0 \%$ sensitivity and $88.0 \%$ specificity at the threshold of $140 \times 10^{9} / \mathrm{L}$, ferritin alone yielded an AUC of 0.587 with $54.0 \%$ sensitivity and $72.0 \%$ specificity at the threshold of $126.30 \mathrm{ng} / \mathrm{mL}$, SHC1 alone yielded an AUC of 0.812 with $82.0 \%$ sensitivity and $64.0 \%$ specificity at the threshold of $8.11 \mathrm{ng} / \mathrm{mL}$, SLAMF8 alone yielded an AUC of 0.684 with $44.0 \%$ sensitivity and $92.0 \%$ specificity at the threshold of 7.30 $\mathrm{ng} / \mathrm{mL}$, IL-32 alone yielded an AUC of 0.741 with $48.0 \%$ sensitivity and $90.0 \%$ specificity at the threshold of $62.37 \mathrm{pg} / \mathrm{mL}$ (Table 3, Fig. 5). When distinguishing HCC patients from LF/LC patients, SLAMF8 was the most outstanding diagnostic parameter in the validation set (AUC=0.802), which was superior to age, PLT, ferritin, SHC1 and IL-32 (AUC=0.758, 0.625, 0.636, 0.646 and 0.761, respectively).

Furthermore, a logistic regression model was constructed to determine the best diagnostic mRNA panel. The predicted probability of the 3-mRNAs panel in combination with clinical parameters was calculated as follows: APFSSI $=-0.1871+0.012 \times$ age $-0.0027 \times$ PLT $+0.0005 \times$ ferritin $+0.1361 \times$ SHC1 $+0.1234 \times$ SLAMF8 $+0.0108 \times$ IL-32. At the threshold of 1.624 , the sensitivity and specificity of APFSSI for CHB diagnosis were $92.0 \%$ and $94.0 \%$ with an AUC of 0.966. Using an APFSSI value of 2.470 as the decision threshold, LF/LC patients could be differentiated from CHB patients with $90.0 \%$ sensitivity and $84.0 \%$ specificity. At a score cut-off of 3.349 , the diagnostic model exhibited $84.0 \%$ sensitivity and $86.0 \%$ specificity for distinguishing HCC patients from LF/LC patients (Table 3, Fig. 5).

\subsection{Establishing the mRNA panel in the test set}

Parameters estimated from the validation set $(n=200)$ were used to evaluate the diagnostic performance of the mRNA panel in the independent test set $(n=400)$. The variables with gradually increasing or decreasing trends were consistent with those in the validation set (Supplemental Table 2). Moreover, the mRNA panel with the highest AUCs showed a better diagnosis for HCC, LF/LC or CHB than other parameters (all $P<0.05$, Supplemental Table 3, Fig. S2). In differentiating CHB from healthy controls, SLAMF8 was regarded as an excellent diagnostic parameter (AUC=0.911), but still inferior to APFSSI model (AUC=0.980) (Supplemental Table 3, Fig. S2). The mRNA panel had a great diagnostic potential for distinguishing LF/LC patients from CHB patients, with $94.0 \%$ sensitivity and 90.0\% specificity. The differentiation power of the APFSSI model for HCC vs. LF/LC (AUC $=0.930$ ) was far superior to SHC1 (AUC=0.744), SLAMF8 (AUC=0.791) and IL-32 (AUC=0.852) (Supplemental Table 3, Fig. S2).

\section{Discussion}


In this real world-based study, the discriminating performance of novel mRNA biomarkers and their panel in patients with $\mathrm{CHB}, \mathrm{LF} / \mathrm{LC}$ and $\mathrm{HCC}$ was investigated, and risk factors associated with the progression of HBV-associated diseases were evaluated. We first applied liver transcriptomics [18] to identify differentially expressed mRNAs as candidate biomarkers for the early detection of HBV-related liver injuries. STEM and WGCNA analyses were employed in the next steps, which can accurately group distinct expression patterns [19] and identify numerous intra-modular hub mRNAs [20, 21] respectively. A total of 9 progressively elevated mRNAs were identified as the hub mRNAs by STEM and WGCNA (Fig. 2). The expression trends of the selected mRNAs were verified by qRT-PCR and immunohistochemistry, which indicated that SHC1, SLAMF8 and IL-32 levels were in line with the sequencing results.

SHC1 belongs to a family of adapter proteins that contain p66Shc, p52Shc and p46Shc isoforms [22, 23]. All these isoforms have been proven to be upregulated in LF [24-26] and HCC [27-29]. As consistent with these studies, our results demonstrated that SHC1 levels in HCC and LF/LC patients were higher than those in CHB patients and healthy individuals. Previously, Yoshida et al. [30] found that p46shc was overexpressed in the cytoplasm and nucleus of tumor cells and/or hepatocytes in HCC rats, whereas p52shc was localized in the cytoplasm. In addition, Huang et al. [27] showed that p66Shc staining was enriched in the cytoplasm. Interestingly, we found that SHC1 was mainly located in the Kupffer cell cytoplasm, and to a lesser extent, in the hepatocellular cytoplasm (Fig. 4). SLAMF8/CD353 is a member of the SLAMF receptor family that modulates the activation and functions of many immune cells [31, 32]. Zeng et al. [33] demonstrated that the combined deficiency of SLAMF8 and SLAMF9 could prevent endotoxin-induced hepatic inflammation and might serve as promising therapeutic targets for acute liver injury. However, our findings demonstrated a significant increase in the expression of SLAMF8 in HBVrelated liver injuries, and its level increased with the severity of these injuries (Fig. 3, 4). IL-32 is a proinflammatory cytokine that contributes to hepatic inflammation and tumor initiation [34, 35]. Previous research has demonstrated that HBV can induce the expression of IL-32 [36]. IL-32 is also upregulated in HBV-infected liver inflammation [35], fibrosis [4] and carcinoma [37]. In our study, compared with healthy controls, patients with severe HBV-related liver diseases exhibited significantly higher levels of IL-32. As IL-32 protein is expressed in almost all hepatocytes and localized in the cytoplasm [37], our IHC staining revealed that IL-32 was found predominantly in the cytoplasm of HBV-associated liver tissues (Fig. 4).

Sensitive and specific biomarkers are essential for the early detection and diagnosis of hepatitis, hepatic fibrosis and HCC, as well as the development of preventive screening [38]. Many researches have been carried out to develop biomarkers, but only a few of them have been translated from the research laboratory into the routine clinical practice $[11,39]$. Considering that plasma-based biomarkers can facilitate the clinical diagnosis of diseases [40], we established a comprehensive mRNA-based model that could be implicated in HCC, LF/LC and CHB. It was found that the plasma levels of 3 identified mRNAs, such as SHC1, SLAMF8 and IL-32, were gradually elevated during the progression of HBV-associated liver diseases (Table 1; Supplemental Table 2). Furthermore, by combining the 3-mRNA panel and 3 clinical parameters, the diagnosis accuracy for differentiating between "HCC and LF/LC", "LF/LC and CHB", and "CHB and healthy controls" could be markedly improved (Fig. 5; Fig. S2). 
Nevertheless, there are some inevitable limitations that need to be addressed. Firstly, the present study was conducted at only one hospital and the findings should be verified in large, multicenter, prospective cohort studies [39]. Secondly, our study was solely focused on Chinese population with HBV-associated liver diseases. Thus, future research is needed to confirm the generalizability of our results by covering other ethnicities, geographical areas, and risk factors, including alcohol abuse, hepatitis $\mathrm{C}$ virus infection, etc [5]. Thirdly, although SHC1, SLAMF8 and IL-32 were stably expressed in plasma, their secretion and transport to the circulation remain largely unclear. Therefore, additional functional studies are warranted to provide a new insight into the molecular mechanisms of the identified mRNAs in HBV-related disease pathogenesis.

\section{Conclusions}

In the present study, we developed a clinically convenient and feasible noninvasive biomarker panel to help detect the potential risks of HCC, LF/LC and CHB via transcriptome sequencing [18]. The primary outcomes of this study are as follows. Firstly, the results of transcriptomic analysis indicated 9 progressively elevated mRNAs during the progression of HBV-related liver injuries. Secondly, the integrated analyses of qRT-PCR and IHC demonstrated that SHC1, SLAMF8 and IL-32 were highly expressed in both liver tissues and PBMCs throughout the courses of HBV-associated liver diseases. Thirdly, we observed significant increases in the plasma levels of SHC1, SLAMF8 and IL-32 in HBVassociated liver diseases compared to healthy controls, and these mRNAs showed gradually increasing trends from CHB to LF/LC and HCC. Fourthly, when analyzed in conjunction with the clinical parameters, SHC1, SLAMF8 and IL-32 remained as independent diagnostic factors for CHB, LF/LC and HCC in a multivariate ordinal regression analysis. Lastly, it was found that the APFSSI model exhibited high diagnostic accuracy in differentiating CHB from healthy subjects, LF/LC patients from CHB patients, and HCC patients from LF/LC patients.

In summary, we performed transcriptome sequencing and bioinformatics analysis to establish a panel of hub mRNAs for HBV-associated liver diseases. Notably, SHC1, SLAMF8 and IL-32 could differentiate between "HCC patients and LF/LC patients", "LF/LC patients and CHB patients", and "CHB patients and healthy controls". To our knowledge, this study is the first to provide threshold points for the selected mRNAs and APFSSI model, which may accelerate their bench to bedside translation and improve the management of HBV-related liver injuries.

\section{Abbreviations}

AFP: alpha fetoprotein, ALB: albumin, ALT: alanine aminotransferase, AST: aspartate aminotransferase, APRI: AST-to-PLT ratio index, AUC: area under the curve, CHB: chronic hepatitis B, Cl: confidence interval, CREA: creatinine, EFEMP1: EGF containing fibulin extracellular matrix protein 1, ELISA: enzyme-linked immunosorbent assay, FIB-4: Fibrosis index based on the 4 factor, GAPDH: Glyceraldehyde-3-phosphate dehydrogenase, GGT: gamma-glutamyl transferase, GO: Gene Ontology, HBV: hepatitis B virus, HBsAg: hepatitis B surface antigen, HCC: hepatocellular carcinoma, HGB: hemoglobin, IHC: 
Immunohistochemical staining, INR: international normalized ratio, IL-32: interleukin-32, ITGB2: integrin subunit beta 2, LF: liver fibrosis, LC: liver cirrhosis, LSM: liver stiffness measurement, MANF:

mesencephalic astrocyte derived neurotrophic factor, PBMCs: peripheral blood mononuclear cells, PLT: platelet, PT: prothrombin time, qRT-PCR: quantitative reverse-transcriptase polymerase chain reaction, ROC: receiver operating characteristic, SHC1: SHC adaptor protein 1, SLAMF8: SLAM family member 8, STEM: short time-series expression miner, SYNPO: synaptopodin, TC2N: tandem C2 domains, nuclear, TBIL: total bilirubin, TOM: topological overlap matrix, UGP2: UDP-glucose pyrophosphorylase 2, WBC: white blood cell, WGCNA: weighted gene co-expression network analysis.

\section{Declarations}

Ethics approval and consent to participate: This study was approved by the local ethics committee of the Third Hospital of Hebei Medical University, and a written informed consent was also obtained from each participant.

Consent for publication: Not applicable.

Availability of data and materials: The data that support the findings of this study are available from the corresponding author upon reasonable request.

Competing interests: We declare that we have no financial and personal relationships with other people or organizations that can inappropriately influence our work.

Funding: The study was supported by the Key Research and Development Program of Hebei Province (No. 19277779D) and the Program of Introduce International Intelligence of Hebei Province.

Authors' contributions: Concept, design, and writing of the article: Dandan Zhao, data collection: Xiaoxiao Zhang, Yuhui Tang, Peilin Guo, Rong Ai, statistical analysis: Mengmeng Hou, Yiqi Wang, Xiwei Yuan, Luyao Cui, literature review and evaluation: Yuguo Zhang, Suxian Zhao, Wencong Li, Yang Wang, Xiaoye Sun, Lingdi Liu, Shiming Dong, Lu Li,Wen Zhao, critical revision of the manuscript and financial support: Yuemin Nan.

Acknowledgements: Not applicable.

\section{References}

1. Sun Z, Liu X, Wu D, Gao H, Jiang J, Yang Y, et al. Circulating proteomic panels for diagnosis and risk stratification of acute-on-chronic liver failure in patients with viral hepatitis $B$. Theranostics. 2019,9(4):1200-14.

2. Wang X, Li MM, Niu Y, Zhang X, Yin JB, Zhao CJ, et al. Serum Zonulin in HBV-Associated Chronic Hepatitis, Liver Cirrhosis, and Hepatocellular Carcinoma. Dis Markers. 2019,2019:5945721. 
3. Li L-J, Wu X-Y, Tan S-W, Xie Z-J, Pan X-M, Pan S-W, et al. Lnc-TCL6 is a potential biomarker for early diagnosis and grade in liver-cirrhosis patients. Gastroenterology Report. 2019,7(6):434-43.

4. Xu H, Zhang S, Pan X, Cao H, Huang X, Xu Q, et al. TIMP-1 expression induced by IL-32 is mediated through activation of AP-1 signal pathway. Int Immunopharmacol. 2016,38:233-7.

5. Cai J, Chen L, Zhang Z, Zhang X, Lu X, Liu W, et al. Genome-wide mapping of 5hydroxymethylcytosines in circulating cell-free DNA as a non-invasive approach for early detection of hepatocellular carcinoma. Gut. 2019,68(12):2195-205.

6. Tseng TC, Liu CJ, Su TH, Yang WT, Chen CL, Yang HC, et al. Fibrosis-4 Index Helps Identify HBV Carriers With the Lowest Risk of Hepatocellular Carcinoma. Am J Gastroenterol. 2017,112(10):156474.

7. Ji D, Chen GF, Wang JC, Cao LH, Lu F, Mu XX, et al. Identification of TAF1, HNF4A, and CALM2 as potential therapeutic target genes for liver fibrosis. Journal of Cellular Physiology. 2018,234(6):904551.

8. Kang YH, Park MY, Yoon DY, Han SR, Lee Cl, Ji NY, et al. Dysregulation of overexpressed IL-32alpha in hepatocellular carcinoma suppresses cell growth and induces apoptosis through inactivation of NFkappaB and Bcl-2. Cancer Lett. 2012,318(2):226-33.

9. Qian X, Liu S, Long H, Zhang S, Yan X, Yao M, et al. Reappraisal of the diagnostic value of alphafetoprotein for surveillance of HBV-related hepatocellular carcinoma in the era of antiviral therapy. Journal of Viral Hepatitis. 2020,28(1):20-9.

10. Wu D, Zhang S, Xie Z, Chen E, Rao Q, Liu X, et al. Plasminogen as a prognostic biomarker for HBVrelated acute-on-chronic liver failure. Journal of Clinical Investigation. 2020,130(4):2069-80.

11. Zhao G, Luo X, Han X, Liu Z. Combining bioinformatics and biological detection to identify novel biomarkers for diagnosis and prognosis of pulmonary tuberculosis. Saudi Medical Journal. 2020,41(4):351-60.

12. Li D, Zhao D, Du J, Dong S, Aldhamin Z, Yuan X, et al. Heme oxygenase-1 alleviated non-alcoholic fatty liver disease via suppressing ROS-dependent endoplasmic reticulum stress. Life Sci. 2020,253:117678.

13. Xu H, Zhang A, Han X, Li Y, Zhang Z, Song L, et al. ITGB2 as a prognostic indicator and a predictive marker for immunotherapy in gliomas. Cancer Immunol Immunother. 2021.

14. Sun Z, Dang Q, Liu Z, Shao B, Chen C, Guo Y, et al. LINC01272/miR-876/ITGB2 axis facilitates the metastasis of colorectal cancer via epithelial-mesenchymal transition. J Cancer. 2021,12(13):390919.

15. Zhang L, Huang Y, Ling J, Zhuo W, Yu Z, Luo Y, et al. Is Integrin Subunit Alpha 2 Expression a Prognostic Factor for Liver Carcinoma? A Validation Experiment Based on Bioinformatics Analysis. Pathol Oncol Res. 2019,25(4):1545-52.

16. He J, Li G, Liu X, Ma L, Zhang P, Zhang J, et al. Diagnostic and Prognostic Values of MANF Expression in Hepatocellular Carcinoma. Biomed Res Int. 2020,2020:1936385. 
17. Liu J, Wu Z, Han D, Wei C, Liang Y, Jiang T, et al. Mesencephalic Astrocyte-Derived Neurotrophic Factor Inhibits Liver Cancer Through Small Ubiquitin-Related Modifier (SUMO)ylation-Related Suppression of NF-kappaB/Snail Signaling Pathway and Epithelial-Mesenchymal Transition. Hepatology. 2020,71(4):1262-78.

18. Baselli GA, Dongiovanni P, Rametta R, Meroni M, Pelusi S, Maggioni M, et al. Liver transcriptomics highlights interleukin-32 as novel NAFLD-related cytokine and candidate biomarker. Gut. 2020,69(10):1855-66.

19. Qi F, Wang L, Huang P, Zhao Z, Yang B, Xia J. Time-series clustering of cytokine expression after transarterial chemoembolization in patients with hepatocellular carcinoma. Oncol Lett. 2020,19(2):1175-86.

20. Liu H, Liu M, You H, Li X, Li X. Oncogenic Network and Hub Genes for Natural Killer/T-Cell Lymphoma Utilizing WGCNA. Frontiers in Oncology. 2020,10.

21. Hendrickx DM, Jennen DG, Briedé JJ, Cavill R, de Kok TM, Kleinjans JC. Pattern recognition methods to relate time profiles of gene expression with phenotypic data: a comparative study. Bioinformatics. 2015,31(13):2115-22.

22. Mir HA, Ali R, Mushtaq U, Khanday FA. Structure-functional implications of longevity protein p66Shc in health and disease. Ageing Res Rev. 2020,63:101139.

23. Grossman SR, Lyle S, Resnick MB, Sabo E, Lis RT, Rosinha E, et al. p66 Shc tumor levels show a strong prognostic correlation with disease outcome in stage IIA colon cancer. Clin Cancer Res. 2007,13(19):5798-804.

24. Ma H, Wang C, Liu X, Zhan M, Wei W, Niu J. Src homolog and collagen homolog1 isoforms in acute and chronic liver injuries. Life Sci. 2021,273:119302.

25. Zhao Y, Wang Z, Zhou J, Feng D, Li Y, Hu Y, et al. LncRNA Mical2/miR-203a-3p sponge participates in epithelial-mesenchymal transition by targeting p66Shc in liver fibrosis. Toxicol Appl Pharmacol. 2020,403:115125.

26. Zhao Y, Wang Z, Feng D, Zhao H, Lin M, Hu Y, et al. p66Shc Contributes to Liver Fibrosis through the Regulation of Mitochondrial Reactive Oxygen Species. Theranostics. 2019,9(5):1510-22.

27. Huang $P$, Feng $X$, Zhao Z, Yang B, Fang T, Guo M, et al. p66Shc promotes HCC progression in the tumor microenvironment via STAT3 signaling. Exp Cell Res. 2019,383(2):111550.

28. Zhang R, Lin XH, Ma M, Chen J, Chen J, Gao DM, et al. Periostin involved in the activated hepatic stellate cells-induced progression of residual hepatocellular carcinoma after sublethal heat treatment: its role and potential for therapeutic inhibition. J Transl Med. 2018,16(1):302.

29. Yoshida S, Kornek M, Ikenaga N, Schmelzle M, Masuzaki R, Csizmadia E, et al. Sublethal heat treatment promotes epithelial-mesenchymal transition and enhances the malignant potential of hepatocellular carcinoma. Hepatology. 2013,58(5):1667-80.

30. Yoshida S, Masaki T, Feng H, Yuji J, Miyauchi Y, Funaki T, et al. Enhanced expression of adaptor molecule p46 Shc in nuclei of hepatocellular carcinoma cells: study of LEC rats. Int J Oncol. 2004,25(4):1089-96. 
31. De Calisto J, Wang N, Wang G, Yigit B, Engel P, Terhorst C. SAP-Dependent and -Independent Regulation of Innate T Cell Development Involving SLAMF Receptors. Front Immunol. 2014,5:186.

32. Sugimoto A, Kataoka TR, Ito H, Kitamura K, Saito N, Hirata M, et al. SLAM family member 8 is expressed in and enhances the growth of anaplastic large cell lymphoma. Sci Rep. 2020,10(1):2505.

33. Zeng X, Liu G, Peng W, He J, Cai C, Xiong W, et al. Combined deficiency of SLAMF8 and SLAMF9 prevents endotoxin-induced liver inflammation by downregulating TLR4 expression on macrophages. Cell Mol Immunol. 2020,17(2):153-62.

34. Hong JT, Son DJ, Lee CK, Yoon DY, Lee DH, Park MH. Interleukin 32, inflammation and cancer. Pharmacol Ther. 2017,174:127-37.

35. Kim DH, Park ES, Lee AR, Park S, Park YK, Ahn SH, et al. Intracellular interleukin-32gamma mediates antiviral activity of cytokines against hepatitis B virus. Nat Commun. 2018,9(1):3284.

36. Tian ZJ, Shen Y, Li XR, Wei YN, Fan H, Ren QK. Increased interleukin-32, interleukin-1, and interferongamma levels in serum from hepatitis B patients and in HBV-stimulated peripheral blood mononuclear cells from healthy volunteers. J Infect Public Health. 2019,12(1):7-12.

37. Zhao WB, Wang QL, Xu YT, Xu SF, Qiu Y, Zhu F. Overexpression of interleukin-32a promotes invasion by modulating VEGF in hepatocellular carcinoma. Oncol Rep. 2018,39(3):1155-62.

38. Zhu HT, Liu RB, Liang YY, Hasan AME, Wang HY, Shao Q, et al. Serum microRNA profiles as diagnostic biomarkers for HBV-positive hepatocellular carcinoma. Liver Int. 2017,37(6):888-96.

39. Gao S, Xu X, Wang Y, Zhang W, Wang X. Diagnostic utility of plasma IncRNA small nucleolar RNA host gene 1 in patients with hepatocellular carcinoma. Mol Med Rep. 2018,18(3):3305-13.

40. Wu D, Zhang P, Ma J, Xu J, Yang L, Xu W, et al. Serum biomarker panels for the diagnosis of gastric cancer. Cancer Medicine. 2019,8(4):1576-83.

\section{Tables}

Table 1. Clinical and laboratory characteristics of the participants in the validation set 
Variables

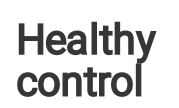

Chronic

Liver

Hepatocellular

Hepatitis B fibrosis/cirrhosis

carcinoma

$\mathrm{F} / \mathrm{Z} / \mathrm{X}^{2} \quad P$

$$
(n=50) \quad(n=50) \quad(n=50) \quad(n=50)
$$

Gender

$21(42.0)$

$28(56.0)$

$37(74.0)^{*}$

$41(82.0)^{\star \#}$

$20.947 \quad 0.000$

$(\%)$

\begin{tabular}{|c|c|c|c|c|c|c|}
\hline $\begin{array}{l}\text { Age } \\
\text { (years) }\end{array}$ & $\begin{array}{l}29.5(24.0- \\
36.0)\end{array}$ & $\begin{array}{l}39.5(31.0- \\
50.0)^{\star}\end{array}$ & $45.5(35.0-54.3)^{\star}$ & $\begin{array}{l}58.0(48.0- \\
66.0)^{\star \# \&}\end{array}$ & 80.658 & 0.000 \\
\hline $\begin{array}{l}\text { WBC } \\
\left(10^{9} / \mathrm{L}\right)\end{array}$ & $5.6 \pm 1.4$ & $5.3 \pm 1.5$ & $4.8 \pm 1.7^{\star}$ & $4.6 \pm 2.0^{\star}$ & 3.832 & 0.011 \\
\hline HGB (g/L) & $\begin{array}{l}140.6 \\
(130.0- \\
154.3)\end{array}$ & $\begin{array}{l}140.3 \\
(130.8- \\
152.6)\end{array}$ & $\begin{array}{l}145.6(129.0- \\
156.2)\end{array}$ & $\begin{array}{l}130.0(111.8- \\
144.0)^{* \# \&}\end{array}$ & 16.342 & 0.001 \\
\hline
\end{tabular}

$\begin{array}{lllllll}\mathrm{PLT} & 240.6 \pm 47.7 & 202.3 \pm 64.6^{*} & 130.7 \pm 70.8^{* \#} & 104.0 \pm 61.0^{* \# \&} & 52.352 & 0.000\end{array}$

$\left(10^{9} / \mathrm{L}\right)$

$\begin{array}{lllllll}\text { ALB }(\mathrm{g} / \mathrm{L}) & 48.7(46.6- & 46.5(44.3- & 42.7(37.5- & 37.7(33.5- & 74.698 & 0.000 \\ & 50.5) & 49.3)^{*} & 47.0)^{\star \#} & 42.9)^{\star * \&} & & \end{array}$

$\begin{array}{lllll}\text { ALT }(\mathrm{U} / \mathrm{L}) & 15.0(12.0- & 26.5(17.5- & 37.0(19.8-85.5)^{*} & 28.0(1 \\ & 25.3) & 51.3)^{\star} & & 50.3)^{\star}\end{array}$

$\begin{array}{lllllll}\text { AST }(U / L) & 17.5(15.0- & 22.5(16.0- & 28.5(20.0- & 36.0(21.8- & 48.053 & 0.000 \\ & 20.0) & 37.0)^{*} & 55.3)^{\star \#} & 59.3)^{\star \#} & & \end{array}$

\begin{tabular}{|c|c|c|c|c|c|c|}
\hline $\begin{array}{l}\text { TBIL } \\
(\mu \mathrm{mol} / \mathrm{L})\end{array}$ & $\begin{array}{l}15.3(13.4- \\
19.2)\end{array}$ & $\begin{array}{l}12.8(11.6- \\
15.6)\end{array}$ & $17.5(12.9-25.7)^{\#}$ & $\begin{array}{l}25.3(13.5- \\
47.9)^{\star \# \&}\end{array}$ & 31.204 & 0.000 \\
\hline $\begin{array}{l}\text { CREA } \\
(\mu \mathrm{mol} / \mathrm{L})\end{array}$ & $\begin{array}{l}67.4(59.5- \\
76.1)\end{array}$ & $\begin{array}{l}64.5(55.7- \\
75.3)\end{array}$ & $63.1(53.5-72.4)$ & $\begin{array}{l}60.7(50.4- \\
77.3)\end{array}$ & 4.106 & 0.250 \\
\hline PT (s) & $10.6 \pm 0.7$ & $11.7 \pm 1.2^{*}$ & $12.2 \pm 1.6^{*}$ & $12.7 \pm 1.7^{\star \#}$ & 6.279 & 0.000 \\
\hline INR & $\begin{array}{l}0.95(0.88- \\
0.99)\end{array}$ & $\begin{array}{l}1.04(0.96- \\
1.13)^{\star}\end{array}$ & $1.05(0.97-1.17)^{\star}$ & $\begin{array}{l}1.12(0.99- \\
1.22)^{\star \#}\end{array}$ & 16.388 & 0.001 \\
\hline $\begin{array}{l}\text { HBV-DNA } \\
\text { (log10 } \\
\text { IU/mL) }\end{array}$ & - & $2.3(1.3-5.6)$ & $2.7(1.3-4.6)$ & $1.4(1.3-2.4)^{\# \&}$ & 7.271 & 0.026 \\
\hline $\begin{array}{l}\text { HBsAg } \\
\text { (log10 } \\
\text { IU } / m L)\end{array}$ & $\begin{array}{l}\text { negative } \\
(31)\end{array}$ & $3.6(3.0-3.9)$ & $2.9(2.5-3.2)^{\#}$ & $2.2(1.8-2.5)^{\# \&}$ & 68.165 & 0.000 \\
\hline $\begin{array}{l}\text { AFP } \\
\text { (ng/mL) }\end{array}$ & $\begin{array}{l}3.2(2.4- \\
4.4)\end{array}$ & $2.7(2.0-3.8)$ & $3.6(2.4-26.6)^{\star \#}$ & $\begin{array}{l}7.2(4.1- \\
528.3)^{\star \# \&}\end{array}$ & 39.000 & 0.000 \\
\hline
\end{tabular}

Ferritin $38.3(30.9-\quad 81.3(42.9-$

$139.7(76.1-$

$227.6(120.1-$

63.883

0.000 


\begin{tabular}{|c|c|c|c|c|c|c|}
\hline (ng/mL) & 70.8) & $159.0)^{*}$ & $231.8)^{\star \#}$ & $541.4)^{* \#}$ & & \\
\hline FIB-4 & $\begin{array}{l}0.52(0.45- \\
0.65)\end{array}$ & $\begin{array}{l}0.92(0.67- \\
1.58)^{\star}\end{array}$ & $\begin{array}{l}1.87(1.08- \\
3.46)^{\star \#}\end{array}$ & $\begin{array}{l}4.58(2.27- \\
9.38)^{\star \# \&}\end{array}$ & 123.462 & 0.000 \\
\hline APRI & $\begin{array}{l}0.18(0.16- \\
0.21)\end{array}$ & $\begin{array}{l}0.30(0.20- \\
0.49)^{*}\end{array}$ & $\begin{array}{l}0.75(0.39- \\
1.16)^{* \#}\end{array}$ & $\begin{array}{l}1.09(0.51- \\
2.55)^{\star \#}\end{array}$ & 99.742 & 0.000 \\
\hline LSM (kPa) & - & $6.3(5.0-7.9)$ & $13.4(9.2-20.2)^{\#}$ & - & 43.938 & 0.000 \\
\hline $\begin{array}{l}\text { SHC1 } \\
(\mathrm{ng} / \mathrm{mL})\end{array}$ & $4.6 \pm 1.3$ & $7.5 \pm 1.7^{\star}$ & $9.7 \pm 1.7^{\star \#}$ & $10.7 \pm 2.0^{* \# \&}$ & 130.768 & 0.000 \\
\hline $\begin{array}{l}\text { SLAMF8 } \\
(\mathrm{ng} / \mathrm{mL})\end{array}$ & $\begin{array}{l}4.9(4.5- \\
5.8)\end{array}$ & $\begin{array}{l}6.1(5.3- \\
6.8)^{\star}\end{array}$ & $6.9(6.1-7.9)^{\star \#}$ & $8.8(7.7-9.4)^{\star \# \&}$ & 95.280 & 0.000 \\
\hline $\begin{array}{l}\text { IL-32 } \\
(\mathrm{pg} / \mathrm{mL})\end{array}$ & $32.3 \pm 11.7$ & $49.1 \pm 13.8^{*}$ & $62.3 \pm 16.0^{* \#}$ & $78.3 \pm 17.5^{\star \# \& ~}$ & 85.705 & 0.000 \\
\hline $\begin{array}{l}\text { ITGB2 } \\
\text { (ug/mL) }\end{array}$ & $63.3 \pm 9.8$ & $81.7 \pm 10.0^{*}$ & $123.5 \pm 12.4^{\star \#}$ & $100.5 \pm 11.9^{\star \# \&}$ & 270.165 & 0.000 \\
\hline $\begin{array}{l}\text { MANF } \\
\text { (ng/mL) }\end{array}$ & $4.5 \pm 0.5$ & $5.3 \pm 0.5^{\star}$ & $7.0 \pm 0.7^{\star \#}$ & $6.1 \pm 0.6^{\star \# \&}$ & 178.425 & 0.000 \\
\hline
\end{tabular}

Note: ${ }^{*} P<0.05$ vs. healthy control, ${ }^{\#} P<0.05$ vs. chronic hepatitis $B$, ${ }^{\&} P<0.05$ vs. liver fibrosis/cirrhosis WBC: white blood cell, HGB: hemoglobin, PLT: platelet, ALB: albumin, ALT: alanine aminotransferase, AST: aspartate aminotransferase, TBIL: total bilirubin, CREA: creatinine, PT: prothrombin time, INR: international normalized ratio, HBsAg: hepatitis B surface antigen, AFP: alpha fetoprotein, FIB-4: Fibrosis index based on the 4 factor, APRI: AST-to-PLT ratio index, LSM: liver stiffness measurement, SHC1: SHC adaptor protein 1, SLAMF8: SLAM family member 8, IL-32: interleukin-32, ITGB2: integrin subunit beta 2, MANF: mesencephalic astrocyte derived neurotrophic factor.

Table 2. Uni- and multi-variate ordinal logistic analyses for the variables extracted by forward selection in the validation set 


\begin{tabular}{lllll} 
Variables & $\begin{array}{l}\text { Univariate ordinal logistic } \\
\text { regression }\end{array}$ & & $\begin{array}{l}\text { Multivariate ordinal logistic } \\
\text { regression }\end{array}$ & \\
\cline { 2 - 5 } & OR $(95 \% \mathrm{Cl})$ & $P$ & OR $(95 \% \mathrm{Cl})$ & $P$ \\
\hline $\begin{array}{l}\text { Gender (male vs } \\
\text { female) }\end{array}$ & $3.487(2.029-5.992)$ & 0.000 & & \\
\hline Age (years) & $1.103(1.079-1.129)$ & 0.000 & $1.071(1.036-1.107)$ & 0.000 \\
\hline WBC $\left(10^{9} / \mathrm{L}\right)$ & $0.773(0.665-0.899)$ & 0.001 & & \\
\hline PLT $\left(10^{9} / \mathrm{L}\right)$ & $0.980(0.976-0.984)$ & 0.000 & $0.988(0.981-0.995)$ & 0.002 \\
\hline ALB $(\mathrm{g} / \mathrm{L})$ & $0.794(0.753-0.838)$ & 0.000 & & \\
\hline AST $(\mathrm{U} / \mathrm{L})$ & $1.017(1.008-1.026)$ & 0.000 & & 0.014 \\
\hline Ferritin $(\mathrm{ng} / \mathrm{mL})$ & $1.006(1.004-1.008)$ & 0.000 & $1.003(1.001-1.006)$ & 0.000 \\
\hline SHC1 $(\mathrm{ng} / \mathrm{mL})$ & $2.456(2.081-2.900)$ & 0.000 & $2.077(1.648-2.618)$ & 0.000 \\
\hline SLAMF8 $(\mathrm{ng} / \mathrm{mL})$ & $2.643(2.152-3.247)$ & 0.000 & $2.104(1.583-2.796)$ & 0.000 \\
\hline IL-32 $(\mathrm{pg} / \mathrm{mL})$ & $1.109(1.087-1.131)$ & 0.000 & $1.054(1.025-1.083)$ & \\
\hline
\end{tabular}

Note: WBC: white blood cell, PLT: platelet, ALB: albumin, AST: aspartate aminotransferase, SHC1: SHC adaptor protein 1, SLAMF8: SLAM family member 8, IL-32: interleukin-32.

Table 3. Comparison of diagnostic performance for age, PLT, ferritin, plasma SHC1, SLAMF8, IL-32 and new models for patients with different stages of disease 
Variables

AUC Cut-off Sensitivity Specificity

Youden

index

\begin{tabular}{|c|c|c|c|c|c|c|}
\hline \multirow[t]{7}{*}{ Chronic hepatitis B } & Age (years) & 0.744 & 36 & 64.0 & 80.0 & 0.440 \\
\hline & $\operatorname{PLT}\left(10^{9} / \mathrm{L}\right)$ & 0.699 & 195 & 56.0 & 90.0 & 0.460 \\
\hline & Ferritin (ng/mL) & 0.688 & 90.598 & 40.0 & 100.0 & 0.400 \\
\hline & $\mathrm{SHC} 1(\mathrm{ng} / \mathrm{mL})$ & 0.900 & 5.025 & 96.0 & 68.0 & 0.640 \\
\hline & SLAMF8(ng/mL) & 0.744 & 4.941 & 88.0 & 52.0 & 0.400 \\
\hline & IL-32(pg/mL) & 0.821 & 48.294 & 56.0 & 98.0 & 0.540 \\
\hline & APFSSI & 0.966 & 1.624 & 92.0 & 94.0 & 0.860 \\
\hline \multirow[t]{7}{*}{ Liver fibrosis/cirrhosis } & Age (years) & 0.592 & 42 & 58.0 & 62.0 & 0.200 \\
\hline & $\operatorname{PLT}\left(10^{9} / \mathrm{L}\right)$ & 0.812 & 140 & 66.0 & 88.0 & 0.540 \\
\hline & Ferritin (ng/mL) & 0.587 & 126.300 & 54.0 & 72.0 & 0.340 \\
\hline & $\mathrm{SHC} 1(\mathrm{ng} / \mathrm{mL})$ & 0.812 & 8.105 & 82.0 & 64.0 & 0.460 \\
\hline & SLAMF8(ng/mL) & 0.684 & 7.302 & 44.0 & 92.0 & 0.360 \\
\hline & IL-32(pg/mL) & 0.741 & 62.367 & 48.0 & 90.0 & 0.380 \\
\hline & APFSSI & 0.924 & 2.470 & 90.0 & 84.0 & 0.740 \\
\hline \multirow{7}{*}{$\begin{array}{l}\text { Hepatocellular } \\
\text { carcinoma }\end{array}$} & Age (years) & 0.758 & 54 & 64.0 & 76.0 & 0.400 \\
\hline & $\operatorname{PLT}\left(10^{9} / \mathrm{L}\right)$ & 0.625 & 97 & 54.0 & 68.0 & 0.220 \\
\hline & Ferritin (ng/mL) & 0.636 & 170.800 & 64.0 & 66.0 & 0.300 \\
\hline & $\mathrm{SHC} 1(\mathrm{ng} / \mathrm{mL})$ & 0.646 & 11.184 & 44.0 & 80.0 & 0.240 \\
\hline & SLAMF8(ng/mL) & 0.802 & 8.286 & 66.0 & 90.0 & 0.560 \\
\hline & IL-32(pg/mL) & 0.761 & 63.841 & 88.0 & 60.0 & 0.480 \\
\hline & APFSSI & 0.904 & 3.349 & 84.0 & 86.0 & 0.700 \\
\hline
\end{tabular}

Note: AUC: area under the curve, PLT: platelet, SHC1: SHC adaptor protein 1, SLAMF8: SLAM family member 8, IL-32: interleukin-32.

\section{Figures}




\section{Study design}

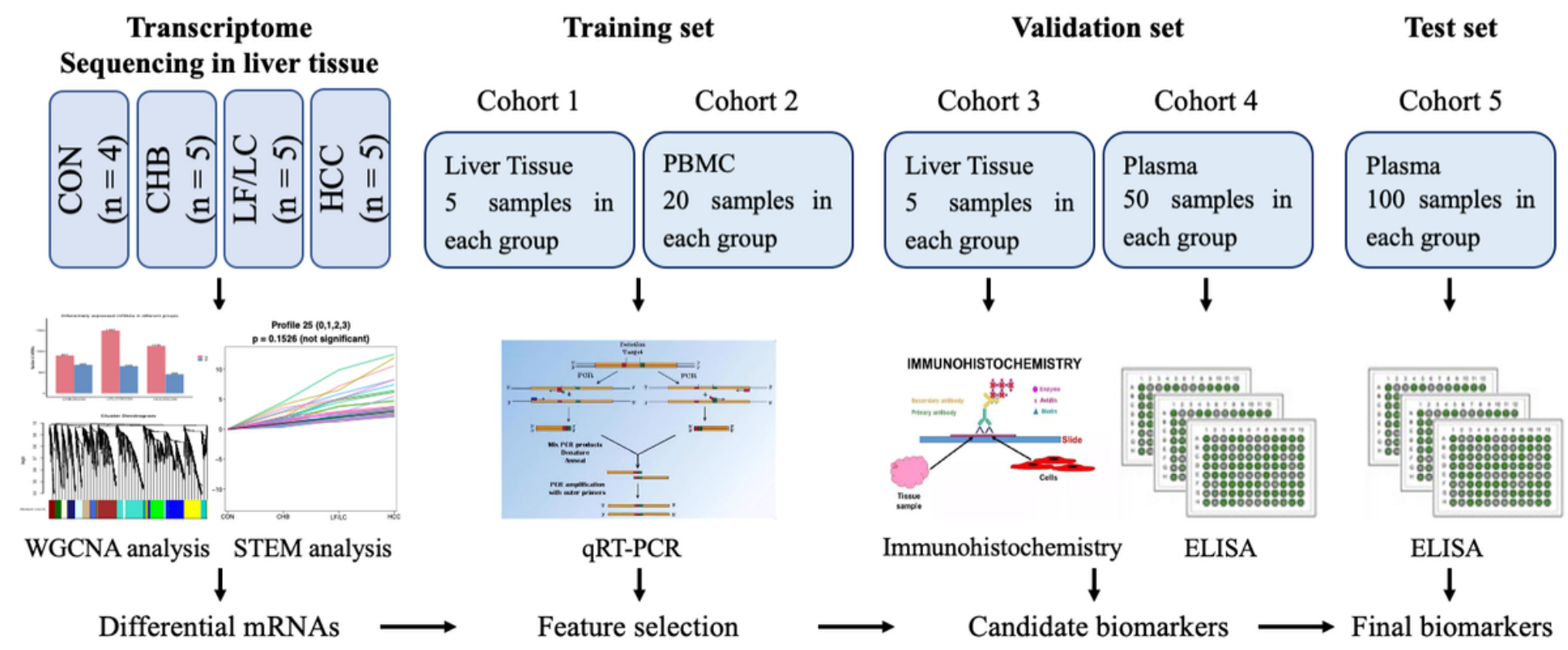

Figure 1

Overall experimental design for plasma biomarker discovery and validation. 

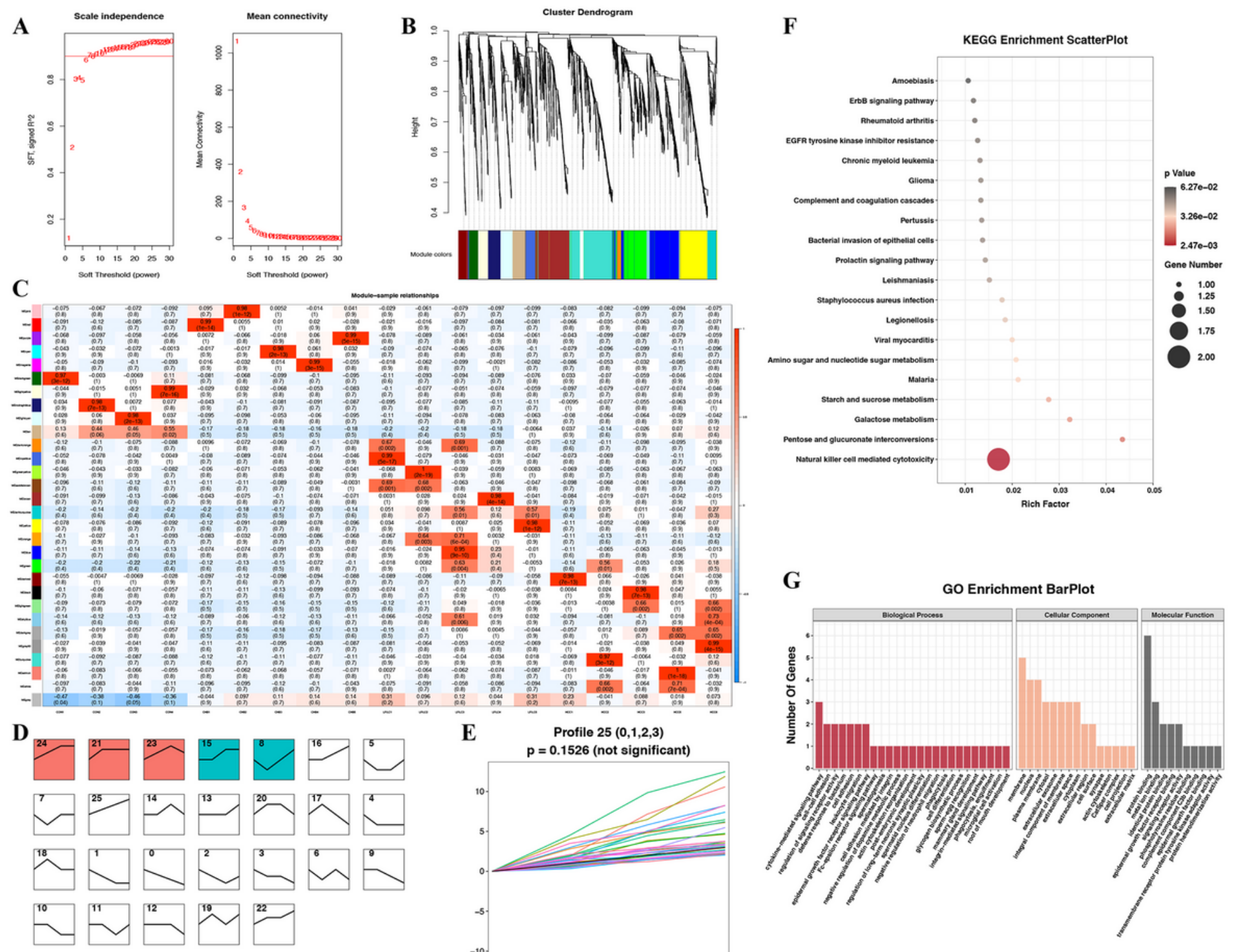

Figure 2

Bioinformatics analysis of transcriptomics data. (A-C) WGCNA of the highly correlated genes in HBVrelated liver diseases. (D, E) STEM identified the temporal expression profiles of mRNAs in the four groups. (F, G) KEGG pathway and GO enrichment analyses of the identified mRNAs. The depth of color and size of black spots denote the adjusted p-value and mRNA quantities, respectively. 
A
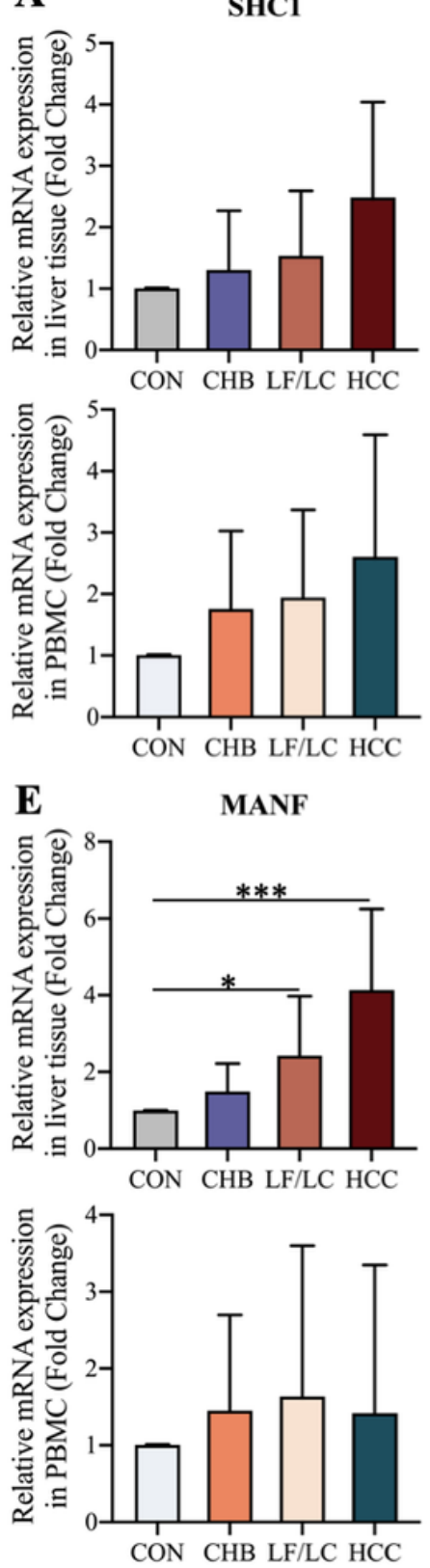

B
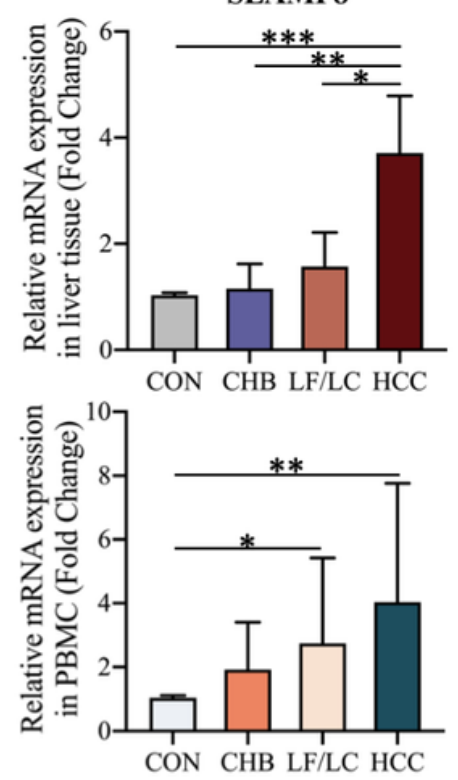

F
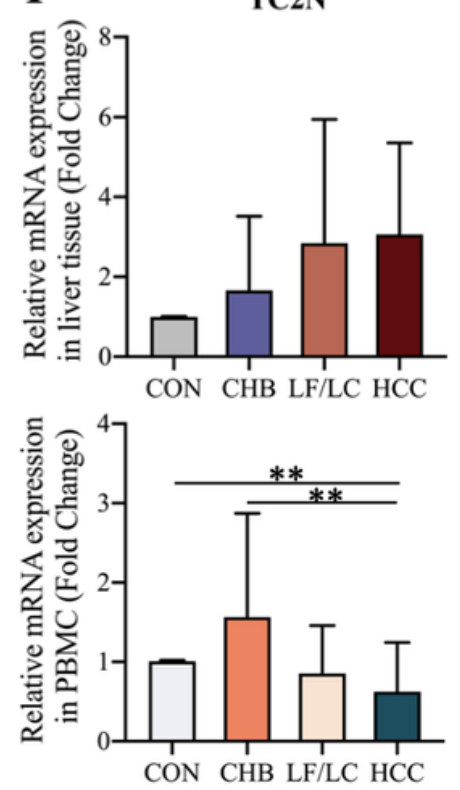

C

IL-32

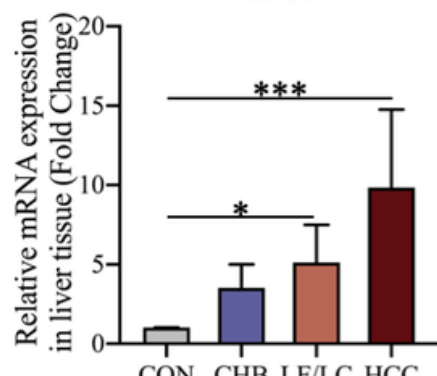

CON CHB LFLLC HCC

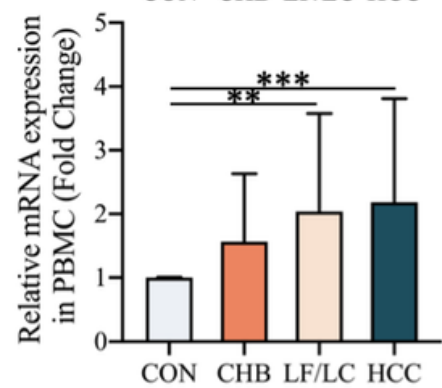

G
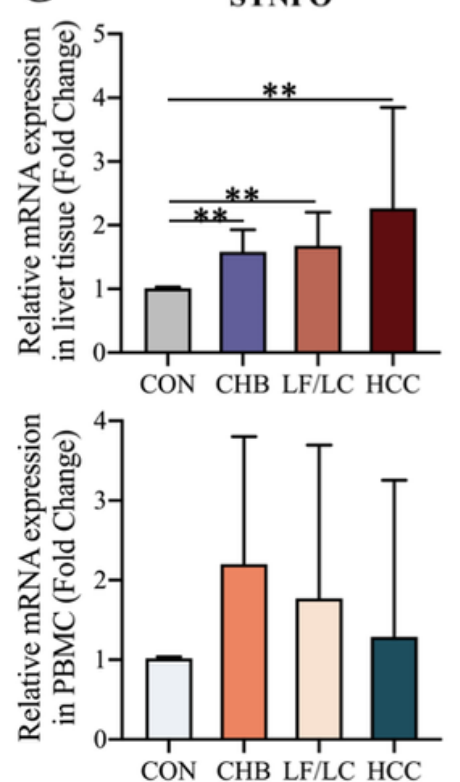

D
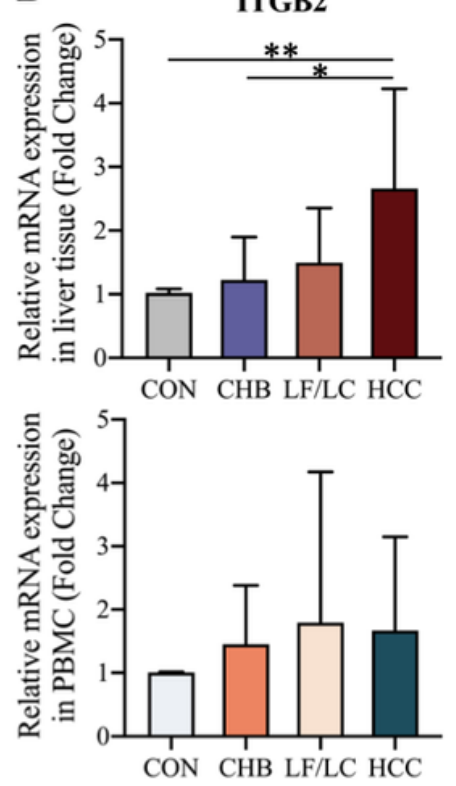

H
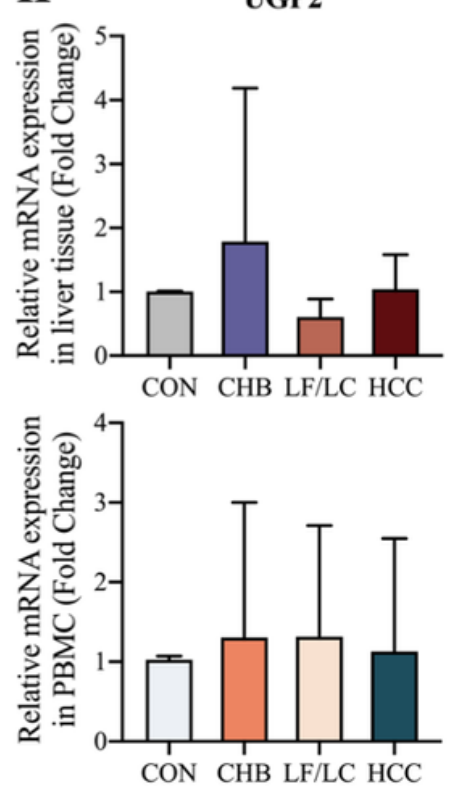

\section{Figure 3}

Relative expression levels of the selected mRNAs in HCC patients, LF/LC patients, CHB patients and control subjects. (A-H) Relative mRNA expression levels in liver tissues and PBMC samples were detected by RT-PCR. 


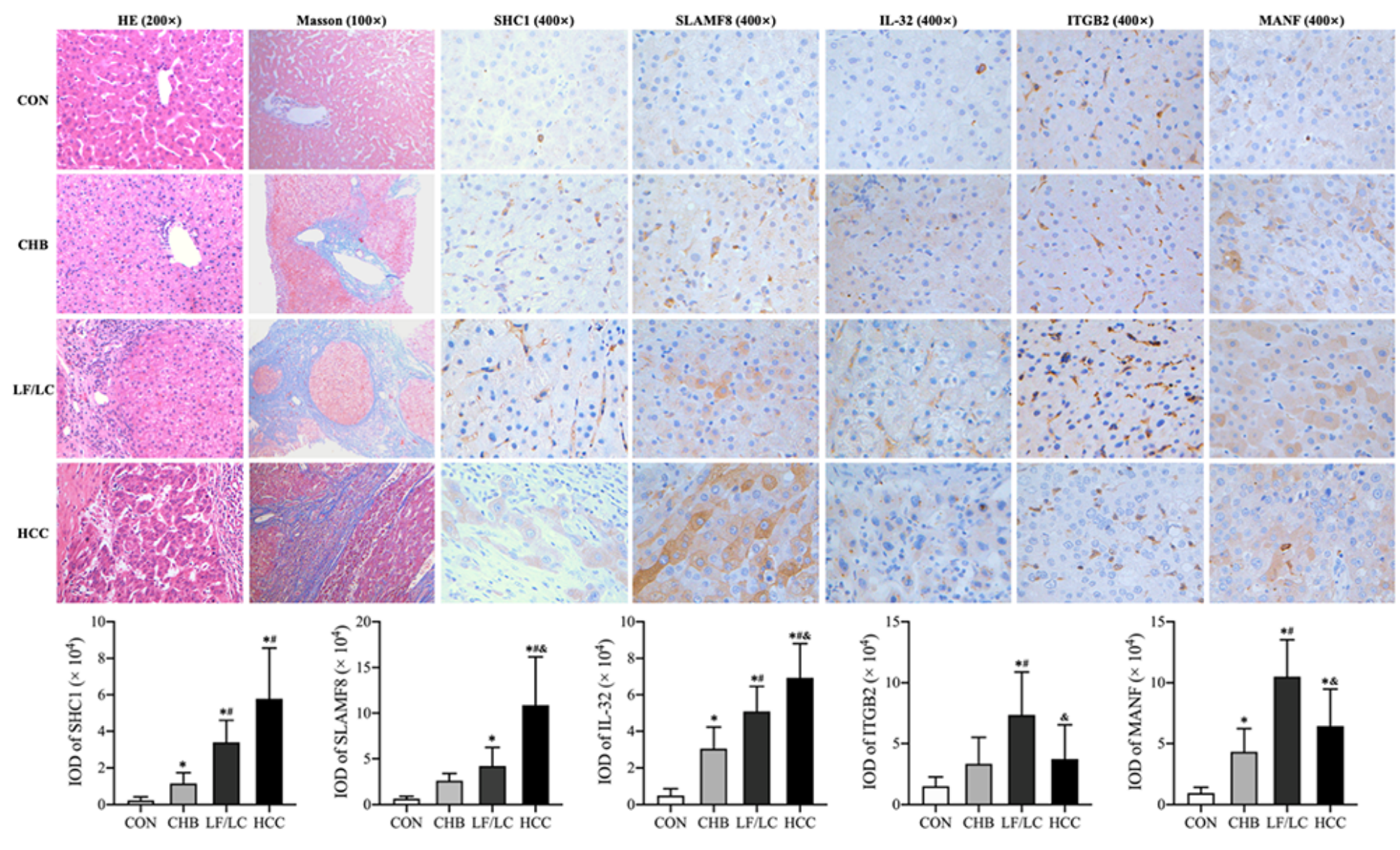

Figure 4

$\mathrm{IHC}$ staining of the liver sections. H\&E staining (magnification, $\times 200)$, Masson staining $(\times 100), \mathrm{IHC}$ staining $(\times 400)$ for SHC1, SLAMF8, IL-32, ITGB2, and MANF. 

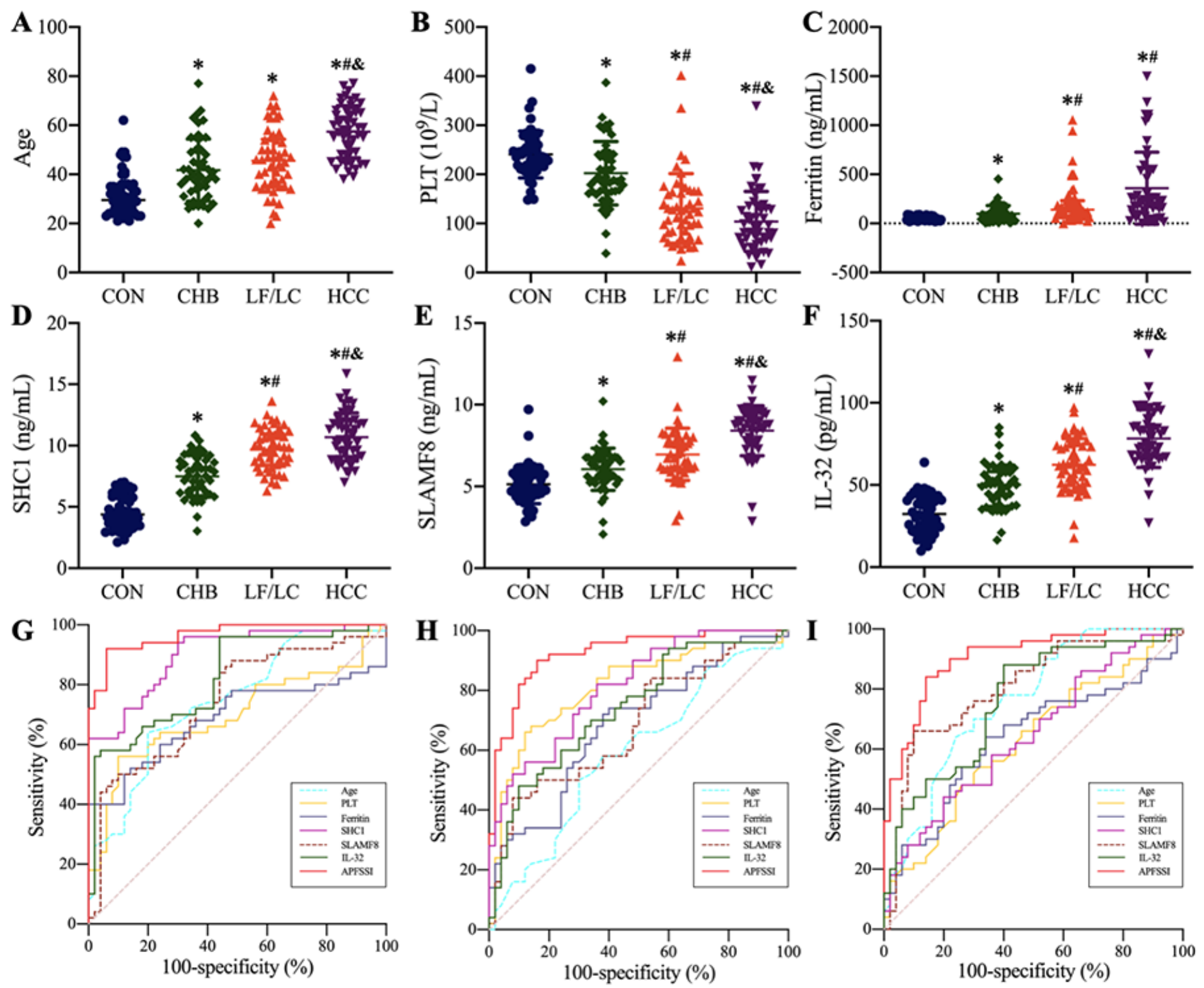

Figure 5

Development and validation of the APFSSI model. The age (A), PLT (B), ferritin content (C), plasma levels of SHC1 (D), SLAMF8 (E) and IL-32 (F) in the four groups. ROC curves for the implications of APFSSI model and other variables to distinguish CHB patients from healthy subjects $(G), L F / L C$ patients from CHB patients $(H)$, and HCC patients from LF/LC patients (I).

\section{Supplementary Files}

This is a list of supplementary files associated with this preprint. Click to download.

- SupplementalFigure1.tiff

- SupplementalFigure2.tiff 
- Supplementalmaterials.docx

Page 24/24 